\title{
Review \\ Developments in the synovial biology field 2006
}

\author{
Anette Knedla, Elena Neumann and Ulf Müller-Ladner
}

\begin{abstract}
Department for Internal Medicine and Rheumatology, Justus-Liebig-University Giessen, Kerckhoff-Clinic, Bad Nauheim, Benekestr. 2-8, D-61231 Bad Nauheim, Germany
\end{abstract}

Corresponding author: Anette Knedla, a.knedla@kerckhoff-klinik.de

Published: 10 April 2007

This article is online at http://arthritis-research.com/content/9/2/209

(c) 2007 BioMed Central Ltd
Arthritis Research \& Therapy 2007, 9:209 (doi:10.1186/ar2140)

the lining layer contains only a small number of blood vessels, and oxygenation and nutrition is facilitated by the blood vessels from the sublining. In diseased synovium, the proliferation of cells (for example, SF) and the infiltration of blood-borne cells (for example, macrophages, B cells, T cells, plasma cells) subsequently result in hypoxic conditions in the tissue because of the increasing distance to a blood vessel and the increased demand for oxygen in the hyperplastic tissue. Neovascularization is thus a prerequisite in the formation and maintenance for the pannus, and intensive neovascularization with blood vessels close to the ultimate lining layer can be observed [4,5]. In addition, there is a close association between rheumatoid synovitis and the formation of complex lymphoid microstructures [6].

At the site of invasion into the adjacent cartilage and bone, the pannus consists mainly of activated fibroblasts. SF mediate also the perichondrocytic cartilage degradation and promote bone destruction by influencing osteoclastogenesis in cooperation with macrophages [7].

As summarized in the present review, numerous researchers have addressed the details of this transition of healthy tissue to diseased synovial tissue. One of the key examples is the work by Steenvorden and colleagues, who have shown that the original epithelial-like phenotype of SF is replaced by a cell showing mesenchymal/fibrotic characteristics, which includes the expression of collagen type $I$ and $\alpha$-smooth muscle actin [8].

As outlined below and shown in Figure 1, the stimulating factors for this development, which have been examined intensively and have revealed numerous novel aspects in the past year, are cell-derived microparticles, hitherto unknown cytokines and chemoattractive molecules.

$\mathrm{IFN}=$ interferon; IKK = I $\beta$ kinase; $\mathrm{IL}=$ interleukin; $\mathrm{MAPK}=$ mitogen-activated protein kinase; $\mathrm{MKK}=$ mitogen-activated protein kinase kinase; $\mathrm{MMP}=$ matrix metalloproteinase; $\mathrm{NF}=$ nuclear factor; RA = rheumatoid arthritis; RANK = receptor activator of nuclear factor $\kappa B$; RANKL $=$ receptor activator of nuclear factor $\mathrm{KB}$ ligand; RASF = rheumatoid arthritis synovial fibroblasts; SF = synovial fibroblasts; TNF = tumor necrosis factor. 
Figure 1

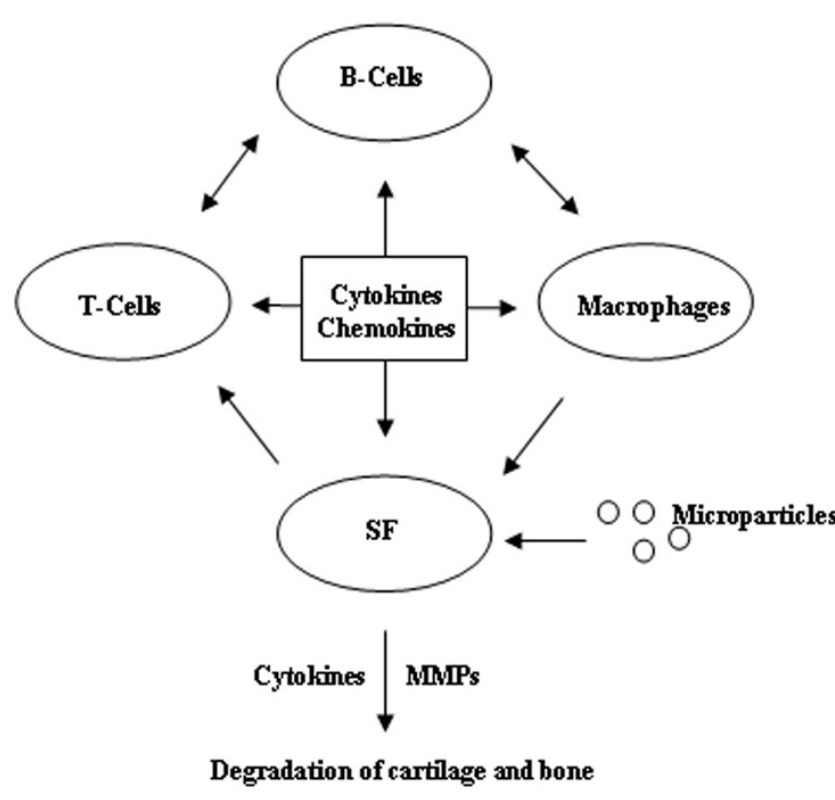

Interactions in the pathophysiology of joint destruction in rheumatoid arthritis. SF, synovial fibroblasts; MMPs, matrix metalloproteinases.

\section{Microparticles}

Microparticles are a heterogeneous population of small membrane-coated vesicles that can be released from all cell types, including macrophages, monocytes, epithelial cells as well as B cells and T cells. Microparticles in synovial fluid were first described by Berckmans and coworkers, who showed that these particles originate mainly from monocytes and granulocytes [9]. The potential function of microparticles in inflammation and as part of mechanisms of the innate immunity was recently reviewed by Distler and colleagues [10].

Microparticles emerge by budding from their parental cells upon apoptosis or activation. The composition of the membrane of the microparticles therefore depends on the cell type of origin. Microparticles inherit all characteristics of the parental cell, including the respective cell surface molecules and receptors, and can therefore act as mediators of cellular interactions. Whether intracellular contents such as cytosolic or nuclear proteins are present within the microparticles or even contribute to their biologic activity remains largely unclear.

In this context, recent findings shed light on these phenomena by indicating that microparticles derived from leukocytes can play a role in inflammatory arthritis by inducing the synthesis of MMPs, chemokines and cytokines in SF $[11,12]$. It could also be shown that, in particular, the synthesis of MMP-1, MMP-3, MMP-9 and MMP-13 was strongly induced by microparticles but the expression of MMP-2, MMP-14 and the tissue inhibitors TIMP-1, TIMP-2 and TIMP-3 was unaffected [13]. Moreover, in the same study it could be demonstrated that microparticles increased the synthesis of IL-6, IL-8 and the monocyte chemoattractant proteins MCP-1 and MCP-2. As was demonstrated recently, bound complement components and activator molecules are present on microparticles ex vivo [14]. In RA synovial fluid, therefore, microparticles might modulate the increased complement activation.

\section{Cytokines}

Increasing evidence was provided in 2006 that the more recently discovered 'novel' cytokines are also involved in promoting joint inflammation in RA. For example, IL-32, which is intensively expressed in RA synovial tissue, resulted in joint inflammation and a mild cartilage damage when injected intraarticularly in murine knee joints [15]. IL-32 was first described by Kim and colleagues [16]. They demonstrated that IL-32 was able to induce the expression of TNF $\alpha, \mathrm{IL}-1 \beta$, IL-6 and several other chemokines in a human acute monocytic leukemia cell line (THP-1), for example, through the cytokine signaling pathways of NF- $\mathrm{KB}$ and p38 mitogenactivated protein kinase (MAPK). IL-32 can therefore be considered a proinflammatory mediator in RA.

IL-1F8, a new member of the IL-1 family that is known to play a pivotal role in immune and inflammatory reactions, also exerts proinflammatory effects in primary human joint cells [17]. Another 'novel' cytokine, IL-17, which is synthesized primarily by $\mathrm{T}$ cells and exhibits proinflammatory activities, has also been associated with RA. Interestingly, it could be shown that IL-17, which is a potent inducer of TNF $\alpha$ and $\mathrm{IL}-1 \beta$, acts independently of TNF $\alpha$ in RA and was able to enhance inflammation and cartilage damage in a TNFdeficient mouse model [18].

A new member of the IL-10 family, IL-20, is known to play a role in skin inflammation and the development of hematopoetic cells. The potential role of IL-20 in RA and arteriosclerosis was recently analyzed by Wei and coworkers [19]. In this context, IL-20 was shown to be upregulated in the synovial fluid of RA patients. Furthermore, in a collageninduced arthritis model in rats it could be shown that both IL-20 and its receptor IL-20RI are present, which confirmed the involvement of IL-20 in the pathogenesis of RA [20]. IL-21 is a CD4+ T-cell-derived cytokine being involved in innate and adaptive immune response. Overexpression of IL-21 and its receptor IL-21R could also be identified in the inflamed synovial membrane and in synovial fluid leukocytes of RA patients [21]. Stimulation of peripheral-blood $T$ cells or synovial-fluid $T$ cells isolated from RA patients with IL-21 resulted in enhanced T-cell activation, proliferation and secretion of proinflammatory cytokines, including TNF $\alpha$ and IFN $\gamma$. Furthermore, it is known that activated macrophages produce central inflammatory cytokines such as TNF $\alpha$ and IL-1. As the anti-inflammatory cytokine IL-10 suppresses the macrophage-dependent synthesis of both TNF $\alpha$ and $\mathrm{IL}-1$ in nonmalignant conditions, it was most interesting to see that 
the responses to IL-10 are dysregulated in RA macrophages, resulting in an inefficient suppression of inflammation [22].

Besides their role in energy metabolism, cytokines derived from adipocytes (for example, adiponectin and resistin) appear to play a pivotal role in the pathogenesis of RA. A strong stimulatory effect of adiponectin on rheumatoid arthritis synovial fibroblasts (RASF) could be detected. Hereby, adiponectin induced IL-6 and MMP-1 in a p38 MAPK pathway-dependent manner [23]. Similarly, it could be shown that an increased concentration of adiponectin in the synovial fluid of RA patients is negatively correlated with the local inflammatory process [24]. Resistin, another so-called adipokine, may also influence proinflammation in RA. For example, an upregulated concentration of resistin was found at local sites of inflammation in arthritis, and the serum resistin levels correlated with inflammation and the activity of the disease in RA [25]. In contrast, circulating levels of the prototype adipocytokine leptin appear not to have a correlation with RA activity $[26,27]$.

\section{Chemokines}

Chemokines are small chemotactic proteins that play a role in the migration of circulating cells into tissue and migration of cells within the tissue. As recently reviewed by Vergunst and colleagues and by Tarrant and Patel, chemokines play a substantial role in the inflammatory process of RA by promoting leukocyte trafficking into the synovium $[28,29]$. The regulation of chemokine ligand CCL18, a T-cell-attracting chemokine, was described by van Lieshout and coworkers [30]. These authors showed that IL-10 in combination with IL4 and IL-13 induced synergistically the secretion of CCL18 in monocytes and monocyte-derived cells. This finding supported the idea that CCL18 is involved in the regulation of the immune system in health and disease.

In several diseases including RA or osteoarthritis, however, chemokines and their receptors are considered potential future therapeutic targets. Based on this idea, a recent study by Haringman and colleagues investigated the expression of the ligands of chemokine receptors CCR1 and CCR5 in the inflamed synovium [31]. They found an abundant expression of both receptors CCR1 and CCR5 in the synovial tissue of RA patients, whereas the percentages of CCR1-positive and CCR5-positive monocytes in the peripheral blood of RA patients were found to be decreased. The blockade of CCR1 and CCR5 could therefore be part of an effective future therapy for RA.

\section{Synovial fibroblasts Pathways to proliferation}

'Receptor cells' of the disease-promoting factors outlined above are mainly synovial fibroblasts and macrophages, which are also the predominant cell types in the inflamed synovium [8,32]. With regard to SF it is not known what initiates the initial proliferation of these cells in the early stages of RA, but this pivotal event can occur prior to the onset of inflammation [33]. In this regard, the investigation of the mode of proliferation revealed an upregulation of the metastatic lymph node MLN51 gene in hyperactive RASF [34]. Even growth-retarded SF showed a significant upregulation of MLN51 when treated with granulocytemacrophage colony-stimulating factor or with synovial fluid. As MLN51 was originally identified in breast cancer, this observation once more emphasizes distinct similarities of the mechanisms of cellular activation in RA and in malignant diseases.

\section{Cell survival and resistance to apoptosis}

Besides unrestricted proliferation, the increasing number of RASF in the synovial lining layer may be also due to an altered apoptosis. It is known that the deficiency or the lack of tumor suppressor genes such as p53, the 'phosphatase and tensin homolog deleted on chromosome 10' PTEN, small ubiquitin-like modifier and p21 leads to long-term cell growth, to extended survival and potentially to tumor formation. Woods and colleagues demonstrated that the cell-cycle inhibitor p21 is significantly reduced in RA synovial lining, particularly in RASF. In addition, p21 is able to repress migration of SF - and, vice versa, loss of p21, which occurs also in RASF, may contribute to the excessive invasion and extended survival of these cells [35]. Moreover, although overexpression of p53 is found in RA synovial tissue, only few synoviocytes undergo apoptosis [36]. This effect could be explained in part by a low expression of proapoptotic genes. In a study from Cha and coworkers using synovial tissue and SF, it could be shown that a deficient p53-upregulated modulator of apoptosis can inhibit apoptosis of SF [37]. Furthermore, the lack of the 'phosphatase and tensin homolog' PTEN in the RA synovial lining was able to contribute to the survival of RASF at sites of destruction [38]. Connor and coworkers showed also that this phenomenon could be due to the PTEN-dependent effect on $1 \kappa B / N F-\kappa B$ interactions and other nuclear factors (for example, akt/protein kinase B).

As recent data indicated a role of protein geranylgeranylation and RhoA/RhoA kinase blocking in regulation of apoptosis, Nagashima and colleagues suggested lipophilic statins as therapeutic agents for RA, since they are able to induce apoptosis in RASF; for example, through mitochondrialdependent and caspase-3-dependent pathways and the inhibition of mevalonate pathways [39]. Moreover, the antiapoptotic molecule myeloid cell leukemia Mcl-1, which is known to be critical for the survival of $\mathrm{T}$ lymphocytes and B lymphocytes and of macrophages [40], appears also to be relevant in the survival of RASF [41].

TNF, being one of the key molecules in driving the inflammatory process in RA synovium, is also linked directly to SF apoptosis. For example, a study conducted by Wang and colleagues [42] revealed that the antiapoptotic effect of 
TNF $\alpha$ in RASF is regulated by the Jun activating binding protein JAB1, because specific knockdown of JAB1 with an antisense RNA construct resulted in TNF $\alpha$-induced apoptosis response in RASF. Moreover, Wang and coworkers showed that this antiapoptotic signaling might be due to a JAB1mediated ubiquitination of TNF-receptor-associated-factor 2 . The potential role of the TNF ligand receptor superfamily in the antiapoptotic pathways in RA was recently reviewed by Hsu and colleagues [43].

\section{Degradation of cartilage and bone}

In 2006 numerous groups supported the idea of RASF being key players in the pathogenesis of RA $[8,32,44]$. For example, a recent study showed that the expression of the extracellular matrix metalloproteinase inducer CD147 was more intensively expressed on RASF than on osteoarthritic SF [45]. The authors concluded that the increased expression of CD147 might be responsible for both the elevated secretion of MMPs and the invasive potential of SF. Of the subsequently activated family members, the collagenases MMP- 1 and MMP-13, the gelatinases MMP-2 and MMP-9, the stromelysin MMP-3 and the membrane-type MMPs can be found in active RA synovium. Of these, the expression of MMP-3 mRNA is higher in diseased RA pannus tissue compared with adjacent nondiseased RA synovium [46]. Most strikingly, although MMP-1 appears to have a function in degrading cartilage collagen type II, it does not appear to derive from pannus tissue but to be secreted by chondrocytes [46]. In addition, in vitro inhibition of the membrane type I MT1-MMP with an antisense RNA construct resulted in a significant reduction of cartilage degradation by RASF [47]. Also, a study by Bauer and colleagues addressing the expression of fibroblast activation protein by RASF revealed that the expression of FAP is colocalized with MMP-1 and MMP-13, indicating that fibroblast activation protein might be an additional factor in cartilage and bone destruction in RA joints [48].

An effective future therapy for RA could be the selective inhibition of MAPK kinases [49]. MKK3 and MKK6 play key roles in the activation of p38 MAPK, which in turn upregulates the expression of cytokines and MMPs in SF. Inoue and colleagues investigated the potential of MKK3 as a therapeutic target. They could show that MKK3 deficiency significantly decreases synovial inflammation and cytokine production in a mouse model of arthritis.

As recently reviewed by Ruocco and Karin, the $\operatorname{I\kappa } \beta$ kinase IKK $\beta$ is essential for the inflammatory cytokine-induced activation of NF-KB [50]. Blocking of IKK $\beta$ could therefore be part of a therapeutic strategy for the treatment of inflammation. In this context, it was demonstrated by Wen and coworkers that the inhibition of IKK $\beta$ with the $\beta$-carboline derivative ML120B inhibits NF-KB signaling in human SF, chondrocytes and mast cells [51]. Moreover, it could be shown that ML120B administration reduces NF-KB activity in rats with induced polyarthritis [52].
RASF play an important role in osteoclast formation [53]. The molecular basis for this property is the synthesis of the ligand for the receptor activator of nuclear factor $\beta$ (RANKL) [54]. Binding of receptor activator of nuclear factor (RANK) with its ligand RANKL regulates the differentiation of bone-resorbing osteoclasts from monocytes/macrophages progenitor cells. In addition, Lee and coworkers revealed that RASF produce actively RANKL, and thus are part of the RANK/RANKL interaction system [55]. Interestingly, a study by Pettit and colleagues demonstrated a focal RANKL, RANK and osteoprotegerin expression in the RA bone microenvironment [56]. Taking these results together, RASF most probably perpetuate actively osteoclastogenesis and bone destruction in RA.

\section{Macrophages Physiological function}

In synovial homeostasis, the physiologic function of macrophages is the induction and regulation of inflammation after infection. Similar to RASF, macrophages are key players in promoting inflammation and joint destruction in RA by secreting proinflammatory cytokines such as IL-1 and TNF $\alpha$ and by the induction and perpetuation of osteoclastogenesis [57]. Macrophages migrate out of the bloodstream as monocytes and accumulate in the synovial membrane. As demonstrated recently, this migratory capacity is dependent on distinct enzymes. Miyata and colleagues showed that, in contrast to osteoarthritis, patients with RA have a significant increase in cathepsin $G$ activity [58]. Interestingly, cathepsin $G$ was able to induce the migration of monocytes in a microchemotaxis chamber and thus cathepsin $G$ appears to promote synovial inflammation in addition to the hydrolytic function of cathepsins in matrix degradation.

With regard to cellular accumulation, Gregory and coworkers showed that macrophage migration inhibitory factor induces the release of CC chemokine ligand 2 from primary microvascular cells [59]. This function of macrophage migration inhibitory factor might therefore further promote the pathogenesis of RA by inducing monocyte migration into the synovium.

\section{Activation}

Activation of macrophages in the RA synovium can take place by several mechanisms [57]; for example, activation by $T$ cells that secrete stimulatory cytokines such as IFN $\gamma$ and IL-2. Direct cell-cell contact between macrophages and $\mathrm{T}$ cells can also result in macrophage activation. In a recent study from Beech and coworkers it was shown that RA synovial T cells are able to induce the chemokine production by monocytes in a cellcontact-dependent manner [60]. Moreover, there appears also to be a correlation between $B$ cells and macrophage activation. Treatment of RA patients with rituximab, a chimeric antibody against CD20-expressing $B$ cells, resulted in a significant decrease of TNF $\alpha$ in the supernatant of isolated human monocyte-derived macrophages [61]. 


\section{Resistance to apoptosis}

Not only fibroblasts but also macrophages appear to be resistant to apoptosis, thereby increasing further the number of macrophages in the synovium. In this context, the antiapoptotic B-cell leukemia Bcl-2 family member $\mathrm{Mcl}-1$ may contribute to the survival of these cells. This was supported by a recent study from Liu and coworkers who revealed an increased expression of $\mathrm{Mcl}-1$ in $\mathrm{CD}^{+} 4^{+}$macrophages derived from the synovial fluid of RA patients. Furthermore, the same group was able to show the induction of apoptosis in synovial macrophages by blocking the PI 3-kinase/Akt-1 or STAT-3 pathways [40].

\section{Osteoclastogenesis}

Macrophages/monocytes are not only involved in inflammatory reactions, but also in the remodeling processes of the bone. Two studies published in the past year provided new insights in the role of monocytes in osteoclast formation. $\mathrm{CD}_{14}{ }^{+}$synovial macrophages isolated from patients with osteoarthritis, RA and pyrophosphate arthropathy have been shown to differentiate into osteoclasts when treated with RANKL [62]. Stimulation with TNF $\alpha$ and IL-1 $\alpha$ resulted in osteoclast formation of macrophages from RA and pyrophosphate arthropathy patients. Another study confirmed the involvement of monocytes as potential precursors of macrophages and osteoclasts. Komano and colleagues revealed that CD16 monocytes, a subset of human peripheral blood monocytes, bear the potential to differentiate into osteoclasts when stimulated with RANKL and macrophage colony-stimulating factor [63].

In 2006, different groups investigated the potential role of the tyrosine kinase inhibitor imatinib in the treatment of RA [64-66]. For example, Ando and colleagues showed that imatinib inhibits the proliferation of macrophage colonystimulating factor-dependent osteoclast precursor cells and the formation of osteoclasts in vitro [64]. Moreover, they showed that the administration of imatinib suppressed joint destruction in a collagen-induced arthritis model in rats. Similarly, it was demonstrated that imatinib enhances osteoclast apoptosis in a cell culture model using rabbit osteoclasts [66]. A recent study by Paniagua and coworkers demonstrated that, in a collagen-induced arthritis model in mice, imatinib affects the proliferation of $B$ cells and monocytes/macrophages, and inhibits several tyrosine kinases that are directly implicated in the pathogenesis of RA [65]. Taken together, the selective inhibition of tyrosine kinases by imatinib could be a promising future therapy for RA.

\section{B cells}

There is increasing evidence that B cells play an important role in the pathogenesis of RA. The production of autoantibodies directed against self-antigens is an important characteristic of RA that can be found prior to the onset of the clinical onset of the disease [67]. Samuels and coworkers were able to show that part of the B-cell-dependent pathophysiology appears to be a failure of the efficient removement of polyreactive $B$ cells in RA and that there are defects at the early B-cell tolerance checkpoint in the bone marrow [68]. Thus, in RA patients the peripheral mature naïve $B$ cells are able to accumulate which then contribute actively to the development of the disease. The importance of $B$ cells in the perpetuation of RA is underlined by the successful treatment of RA patients with biologic agents and drugs selectively affecting $B$ cells.

As recently reviewed by Keystone and by Looney, the targeting and depletion of $\mathrm{B}$ cells with a mouse-human chimeric monoclonal antibody against the B-cell-specific antigen CD20 resulted in a significant beneficial effect in RA patients $[69,70]$. Moreover, treatment of RA patients with a fully human monoclonal antibody against the B-lymphocyte stimulator, which is a growth and survival factor for B cells, appears to be a promising therapy for the future [71].

\section{T cells}

As recently reviewed by Leipe and coworkers and by Skapenko and colleagues, T cells play an important role in the pathogenesis of RA [72,73]. An important subset of regulatory $\mathrm{T}$ cells is $\mathrm{CD} 4{ }^{+} \mathrm{CD} 25^{+} \mathrm{T}$ cells, which are known to control the development of autoimmune diseases. This cell population is enriched in synovial fluid of RA patients but appears to be reduced in peripheral blood. Moreover, the lack of $\mathrm{CD}^{+}{ }^{+} \mathrm{CD} 25^{+} \mathrm{T}$ cells in peripheral blood can be observed in early active RA [74].

Several studies addressed the paradox that although the number of inhibitory regulatory $T$ cells is increased in synovial fluid, inflammation still occurs in the rheumatoid joint. In this regard, Sakaguchi and colleagues reported that complete depletion of the regulatory T-cell transcription factor FOXP3 was able to activate even weak or rare self-reactive T-cell clones and to induce severe autoimmune diseases [75]. Another review published in 2006 discusses the function of cytokines in the generation and maintenance of regulatory T cells [76]. In this context, a recent study from Zorn and coworkers underlined the potential role of $\mathrm{IL}-2$ in the maintenance of $\mathrm{FOXP3}{ }^{+} \mathrm{CD} 4{ }^{+} \mathrm{CD} 25^{+}$regulatory $\mathrm{T}$ cells [77]. It could be shown that IL-2 upregulated selectively the expression of FOXP3 in an in vitro culture of CD4 ${ }^{+} \mathrm{CD} 25^{+}$ T cells. With regard to a potential therapeutic approach, Gonzalez-Rey and colleagues determined the ability of vasoactive intestinal peptide to induce functional regulatory T cells in the collagen-induced arthritis mouse model [78]. They were able to show that the administration of vasoactive intestinal peptide resulted in the expansion of $\mathrm{FOXP} 3^{+} \mathrm{CD} 4{ }^{+} \mathrm{CD} 25^{+}$regulatory $\mathrm{T}$ cells, including the joints. The vasoactive intestinal peptide-triggered transfer of the regulatory $T$ cells suppressed the progression of the disease, and might therefore bear the potential to suit as a therapeutic tool in the future. 
The important role of cytokines in the development and chronic progression of CD4 ${ }^{+} \mathrm{T}$-cell-mediated chronic autoimmune disease was also demonstrated in the novel animal model for RA, the Sakaguchi SKG mice [79]. Hata and coworkers showed that the synovial fluid of arthritic SKG mice contain high concentrations of IL-6, TNF $\alpha$ and IL-1. Furthermore, their study revealed that the deficiency in either IL-6, IL-1 or TNF $\alpha$ can inhibit the development and the progression of arthritis in this mouse model, whereas IL-10 deficiency leads to an exacerbation of the disease. A recently published study by Hirota and coworkers provided evidence that IL-6 is a key factor in the differentiation process of selfreactive $\mathrm{T}$ cells [80]. These authors could demonstrate in a mouse model that self-reactive $T$ cells stimulate antigenpresenting cells to secrete IL-6. Together with $T$ cells, antigen-presenting cells form an IL-6 cytokine milieu, which drives naïve self-reactive $T$ cells to differentiate into IL-17secreting CD4+ helper T cells (Th17 cells). Moreover, it was shown that IL-17 or IL-6 deficiency leads to a complete inhibition of arthritis.

\section{Conclusion}

The past year has contributed significantly to the deeper understanding of synovial biology. Of the various aspects that have been addressed, predominantly extracellular pathways including novel cytokines, adipokines and chemokines as well as stimulating microparticles have been introduced in this fascinating field. Among the various cellular players, fibroblasts, macrophages, $T$ cells and $B$ cells especially have been in the scope of interest of worldwide rheumatology research - which has identified numerous hitherto unknown mechanisms involved in the activation and proliferation of these cells and their interaction with other articular components.

\section{Competing interests}

The authors declare that they have no competing interests.

\section{References}

1. Smith M, Barg E, Weedon H, Papangelis V, Smeets T, Tak PP, Kraan M, Coleman M, Ahern M: Microarchitecture and protective mechanisms in synovial tissue from clinically and arthroscopically normal knee joints. Ann Rheum Dis 2003, 62: 303-307.

2. Qu Z, Garcia C, O'Rourke L, Planck S, Kohli M, Rosenbaum J: Local proliferation of fibroblast-like synoviocytes contributes to synovial hyperplasia. Results of proliferating cell nuclear antigen/cyclin, c-myc, and nucleolar organizer region staining. Arthritis Rheum 1994, 37:212-220.

3. Kraan M, Versendaal H, Jonker M, Bresnihan B, Post W, t Hart B, Breedveld F, Tak P: Asymptomatic synovitis precedes clinically manifest arthritis. Arthritis Rheum 1998, 41:1481-1488.

4. Paleolog EM: Angiogenesis in rheumatoid arthritis. Arthritis Res Ther 2002, 4:S81-S90.

5. Roccaro A, Russo F, Cirulli T, Di Pietro G, Vacca A, Dammacco F: Antiangiogenesis for rheumatoid arthritis. Curr Drug Targets Inflamm Allergy 2005, 4:27-30.

6. Takemura S, Braun A, Crowson C, Kurtin PJ, Cofield RH, O'Fallon WOM, Goronzy JJ, Weyand CM: Lymphoid neogenesis in rheumatoid synovitis. J Immuno/ 2001, 167:1072-1080.

7. Karouzakis E, Neidhart M, Gay R, Gay S: Molecular and cellular basis of rheumatoid joint destruction. Immunol Lett 2006, 106: 8-13.
8. Steenvoorden M, Tolboom T, van der Pluijm G, Lowik C, Visser C, Degroo $t J$, Gittenberger-Degroot A, Deruiter M, Wisse B, Huizinga $\mathrm{T}$, et al.: Transition of healthy to diseased synovial tissue in rheumatoid arthritis is associated with gain of mesenchymal/fibrotic characteristics. Arthritis Res Ther 2006, 8:R165.

9. Berckmans RJ, Nieuwland R, Tak PP, Boing AN, Romijn FP, Kraan MC, Breedveld FC, Hack CE, Sturk A: Cell-derived microparticles in synovial fluid from inflamed arthritic joints support coagulation exclusively via a factor VII-dependent mechanism. Arthritis Rheum 2002, 46:2857-2866.

10. Distler J, Pisetsky D, Huber L, Kalden J, Gay S, Distler O: Microparticles as regulators of inflammation: novel players of cellular crosstalk in the rheumatic diseases. Arthritis Rheum 2005, 52:3337-3348.

11. Distler J, Huber L, Gay S, Distler O, Pisetsky D: Microparticles as mediators of cellular cross-talk in inflammatory disease. Autoimmunity 2006, 39:683-690.

12. Berckmans RJ, Nieuwland R, Kraan MC, Schaap MC, Pots D, Smeets TJ, Sturk A, Tak PP: Synovial microparticles from arthritic patients modulate chemokine and cytokine release by synoviocytes. Arthritis Res Ther 2005, 7:R536-R544.

13. Distler J, Jüngel $A$, Huber L, Seemayer $C$, Reich $C$, Gay R, Michel B, Fontana A, Gay S, Pisetsky D, et al.: The induction of matrix metalloproteinase and cytokine expression in synovial fibroblasts stimulated with immune cell microparticles. Proc Nat Acad Sci U S A 2005, 102:2892-2897.

14. Biro E, Nieuwland R, Tak PP, Pronk LM, Schaap MC, Sturk A, Hack CE, Activated complement components and complement activator molecules on the surface of cell-derived microparticles in patients with rheumatoid arthritis and healthy individuals. Ann Rheum Dis 2007 [Epub ahead of print].

15. Joosten L, Netea M, Kim S, Yoon D, Oppers-Walgreen B, Radstake T, Barrera P, van de Loo F, Dinarello C, van den Berg W: IL32, a proinflammatory cytokine in rheumatoid arthritis. Proc Natl Acad Sci U S A 2006, 103:3298-3303.

16. Kim S, Han S, Azam T, Yoon D, Dinarello C: Interleukin-32: a cytokine and inducer of TNF $\alpha$. Immunity 2005, 22:131-142.

17. Magne D, Palmer G, Barton J, Mezin F, Talabot-Ayer D, Bas S, Duffy T, Noger M, Guerne P, Nicklin M, et al.: The new IL-1 family member IL-1F8 stimulates production of inflammatory mediators by synovial fibroblasts and articular chondrocytes. Arthritis Res Ther 2006, 8:R80.

18. Koenders M, Lubberts E, van de Loo F, Oppers-Walgreen B, van den Bersselaar L, Helsen M, Kolls J, Di Padova F, Joosten L, van den Berg W: Interleukin-17 acts independently of TNF- $\alpha$ under arthritic conditions. J Immunol 2006, 176:6262-6269.

19. Wei C, Hsu Y, Li H, Wang Y, Hsieh M, Chen W, Hsing C, Chang M: IL-20: biological functions and clinical implications. J Biomed Sci 2006, 13:601-612.

20. Hsu Y, Li H, Hsieh M, Liu M, Huang K, Chin L, Chen P, Cheng H, Chang $\mathrm{M}$ : Function of interleukin-20 as a proinflammatory molecule in rheumatoid and experimental arthritis. Arthritis Rheum 2006, 54:2722-2733.

21. Li J, Shen W, Kong K, Liu Z: Interleukin-21 induces T-cell activation and proinflammatory cytokine secretion in rheumatoid arthritis. Scand J Immunol 2006, 64:515-522.

22. Antoniv T, Ivashkiv L: Dysregulation of interleukin-10-dependent gene expression in rheumatoid arthritis synovial macrophages. Arthritis Rheum 2006, 54:2711-2721.

23. Ehling A, Schaffler A, Herfarth $H$, Tarner I, Anders S, Distler O, Paul G, Distler J, Gay S, Scholmerich J, et al.: The potential of adiponectin in driving arthritis. J Immunol 2006, 176:44684478.

24. Senolt L, Pavelka K, Housa D, Haluzik M: Increased adiponectin is negatively linked to the local inflammatory process in patients with rheumatoid arthritis. Cytokine 2006, 35:247252.

25. Senolt L, Housa D, Vernerova Z, Jirasek T, Svobodova R, Veigl D, Anderlova K, Muller-Ladner U, Pavelka K, Haluzik M: Resistin in rheumatoid arthritis synovial tissue, synovial fluid and serum. Ann Rheum Dis 2007, 66:458-463.

26. Gunaydin R, Kaya T, Atay A, Olmez N, Hur A, Koseoglu M: Serum leptin levels in rheumatoid arthritis and relationship with disease activity. South Med J 2006, 99:1078-1083.

27. Hizmetli S, Kisa M, Gokalp N, Bakici M: Are plasma and synovial fluid leptin levels correlated with disease activity in rheumatoid arthritis? Rheumatol Int 2007, 27:335-338. 
28. Vergunst CE, van de Sande MGH, Lebre MC, Tak PP: The role of chemokines in rheumatoid arthritis and osteoarthritis. Scand $J$ Rheumato/ 2005, 34:415-425.

29. Tarrant T, Patel D: Chemokines and leukocyte trafficking in rheumatoid arthritis. Pathophysiology 2006, 13:1-14.

30. van Lieshout $A$, van der Voort R, le Blanc $L$, Roelofs $M$, Schreurs $B$, van Riel P, Adema G, Radstake T: Novel insights in the regulation of CCL18 secretion by monocytes and dendritic cells via cytokines, toll-like receptors and rheumatoid synovial fluid. BMC Immunol 2006, 7:23.

31. Haringman J, Smeets T, Reinders-Blankert P, Tak P: Chemokine and chemokine receptor expression in paired peripheral blood mononuclear cells and synovial tissue of patients with rheumatoid arthritis, osteoarthritis, and reactive arthritis. Ann Rheum Dis 2006, 65:294-300.

32. Meinecke I, Rutkauskaite E, Gay S, Pap T: The role of synovial fibroblasts in mediating joint destruction in rheumatoid arthritis. Curr Pharm Des 2005, 11:563-568.

33. Ospelt C, Neidhart M, Gay RE, Gay S: Synovial activation in rheumatoid arthritis. Front Biosci 2004, 9:2323-2334.

34. Jang J, Lim D-S, Choi Y-E, Jeong Y, Yoo S-A, Kim W-U, Bae Y-S: MLN51 and GM-CSF involvement in the proliferation of fibroblast-like synoviocytes in the pathogenesis of rheumatoid arthritis. Arthritis Res Ther 2006, 8:R170.

35. Woods J, Klosowska K, Spoden D, Stumbo N, Paige D, Scatizzi J, Volin M, Rao M, Perlman H: A cell-cycle independent role for p21 in regulating synovial fibroblast migration in rheumatoid arthritis. Arthritis Res Ther 2006, 8:R113.

36. Seemayer CA, Kuchen S, Neidhart M, Kuenzler P, Rihosková V, Neumann E, Pruschy M, Aicher WK, Müller-Ladner U, Gay RE, et al:: p53 in rheumatoid arthritis synovial fibroblasts at sites of invasion. Ann Rheum Dis 2003, 62:1139-1144.

37. Cha H, Rosengren S, Boyle D, Firestein GS: PUMA regulation and proapoptotic effects in fibroblast-like synoviocytes. Arthritis Rheum 2006, 54:587-592.

38. Connor A, Berger S, Narendam A, Keystone E: Inhibition of protein geranylgeranylation induces apoptosis in synovial fibroblasts. Arthritis Res Ther 2006, 8:R94.

39. Nagashima T, Okazaki H, Yudoh K, Matsuno H, Minota S: Apoptosis of rheumatoid synovial cells by statins through the blocking of protein geranylgeranylation: a potential therapeutic approach to rheumatoid arthritis. Arthritis Rheum 2006, 54: 579-586.

40. Liu H, Huang Q, Shi B, Eksarko P, Temkin V, Pope RM: Regulation of $\mathrm{Mcl}-1$ expression in rheumatoid arthritis synovial macrophages. Arthritis Rheum 2006, 54:3174-3181.

41. Liu H, Eksarko P, Temkin V, Haines GR, Perlman H, Koch A Thimmapaya B, Pope R: Mcl-1 is essential for the survival of synovial fibroblasts in rheumatoid arthritis. J Immunol 2005, 175:8337-8345.

42. Wang J, Li C, Liu Y, Mei W, Yu S, Zhang L, Cao X, Kimberly R, Grizzle W, Zhang $H$ : JAB1 determines the response of rheumatoid arthritis synovial fibroblasts to tumor-necrosis factor- $\alpha$. Am J Pathol 2006, 169:889-902.

43. Hsu $\mathrm{H}, \mathrm{Wu} \mathrm{Y}$, Mountz J: Tumor necrosis factor ligand-receptor superfamily and arthritis. Curr Dir Autoimmun 2006, 9:37-54.

44. Huber L, Distler O, Tarner I, Gay RE, Gay S, Pap T: Synovial fibroblasts: key players in rheumatoid arthritis. Rheumatology 2006, 45:669-675.

45. Zhu P, Lu N, Shi Z, Zhou J, Wu Z, Yang Y, Ding J, Chen Z: CD147 overexpression on synoviocytes in rheumatoid arthritis enhances matrix metalloproteinase production and invasiveness of synoviocytes. Arthritis Res Ther 2006, 8:R44.

46. Ainola MM, Mandelin JA, Liljeström MP, Li T-F, Hukkanen MVJ, Konttinen YT: Pannus invasion and cartilage degradation in rheumatoid arthritis: involvement of MMP-3 and interleukin13. Clin Exp Rheumatol 2005, 23:644-650.

47. Rutkauskaite E, Volkmer D, Shigeyama Y, Schedel J, Pap G, Muller-Ladner U, Meinecke I, Alexander D, Gay R, Drynda S, et al.: Retroviral gene transfer of an antisense construct against membrane type 1 matrix metalloproteinase reduces the invasiveness of rheumatoid arthritis synovial fibroblasts. Arthritis Rheum 2005, 52:2010-2014.

48. Bauer S, Jendro M, Wadle A, Kleber S, Stenner F, Dinser R, Reich A, Faccin E, Godde S, Dinges $\mathrm{H}$, et al.: Fibroblast activation protein is expressed by rheumatoid myofibroblast-like synoviocytes. Arthritis Res Ther 2006, 8:R171.
49. Inoue T, Boyle DL, Corr M, Hammaker D, Davis RJ, Flavell RA, Firestein GS: Mitogen-activated protein kinase kinase 3 is a pivotal pathway regulating p38 activation in inflammatory arthritis. Proc Natl Acad Sci U S A 2006, 103:5484-5489.

50. Ruocco MG, Karin M: IKK $\beta$ as a target for treatment of inflammation induced bone loss. Ann Rheum Dis, 200564 (Suppl 4): iv81-iv85.

51. Wen D, Nong Y, Morgan JG, Gangurde $P$, Bielecki A, Dasilva J, Keaveney $\mathrm{M}$, Cheng $\mathrm{H}$, Fraser $\mathrm{C}$, Schopf $\mathrm{L}$, et al:: A selective small molecule IKB kinase $\beta$ inhibitor blocks nuclear factor kB-mediated inflammatory responses in human fibroblastlike synoviocytes, chondrocytes, and mast cells. J Pharmacol Exp Ther 2006, 317:989-1001

52. Schopf L, Savinainen A, Anderson K, Kujawa J, DuPont M, Silva $\mathrm{M}$, Siebert E, Chandra S, Morgan J, Gangurde P, et al:: IKK $\beta$ inhibition protects against bone and cartilage destruction in a rat model of rheumatoid arthritis. Arthritis Rheum 2006, 54:31633173.

53. Neumann E, Gay S, Muller-Ladner U: The RANK/RANKL/osteoprotegerin system in rheumatoid arthritis: new insights from animal models. Arthritis Rheum 2005, 52:2960-2967.

54. Shigeyama Y, Pap T, Kunzler P, Simmen B, Gay RE, Gay S: Expression of osteoclast differentiation factor in rheumatoid arthritis. Arthritis Rheum 2000, 43:2523-2530.

55. Lee H, Jeon H, Song E, Han M, Park S, Lee S, Yun H, Kim J, Kim $J$, Lee $\mathrm{Y}$, et al.: CD40 ligation of rheumatoid synovial fibroblasts regulates RANKL-mediated osteoclastogenesis: evidence of NF-KB-dependent, CD40-mediated bone destruction in rheumatoid arthritis. Arthritis Rheum 2006, 54:1747-1758.

56. Pettit A, Walsh N, Manning C, Goldring S, Gravallese E: RANKL protein is expressed at the pannus-bone interface at sites of articular bone erosion in rheumatoid arthritis. Rheumatology 2006, 45:1068-1076.

57. Ma Y, Pope RM: The role of macrophages in rheumatoid arthritis. Curr Pharm Des 2005, 11:569-580.

58. Miyata J, Tani K, Sato K, Otsuka S, Urata T, Lkhagvaa B, Furukawa C, Sano N, Sone S: Cathepsin G: the significance in rheumatoid arthritis as a monocyte chemoattractant. Rheumatol Int 2007, 27:375-382.

59. Gregory J, Morand E, McKeown S, Ralph J, Hall P, Yang Y, McColl S, Hickey M: Macrophage migration inhibitory factor induces macrophage recruitment via CC chemokine ligand 2. $\mathrm{J}$ Immuno/ 2006, 177:8072-8079.

60. Beech J, Andreakos E, Ciesielski C, Green P, Foxwell B, Brennan F: T-cell contact-dependent regulation of $\mathrm{CC}$ and $\mathrm{CXC}$ chemokine production in monocytes through differential involvement of NFKB: implications for rheumatoid arthritis. Arthritis Res Ther 2006, 8:R168.

61. Toubi E, Kessel A, Slobodin G, Boulman N, Pavlotzky E, Zisman $D$, Rozenbaum M, Rosner I: Macrophage function changes following rituximab treatment in patients with rheumatoid arthritis. Ann Rheum Dis 2006 [Epub ahead of print].

62. Adamopoulos I, Sabokbar A, Wordsworth B, Carr A, Ferguson D, Athanasou N: Synovial fluid macrophages are capable of osteoclast formation and resorption. Am J Pathol 2006, 208: 35-43.

63. Komano Y, Nanki T, Hayashida K, Taniguch K, Miyasaka N: Identification of a human peripheral blood monocyte subset that differentiates into osteoclasts. Arthritis Res Ther 2006, 8:R152.

64. Ando $W$, Hashimoto J, Nampei A, Tsuboi H, Tateishi K, Ono T, Nakamura N, Ochi T, Yoshikawa H: Imatinib mesylate inhibits osteoclastogenesis and joint destruction in rats with collageninduced arthritis (CIA). J Bone Miner Metab 2006, 24:274-282.

65. Paniagua RT, Sharpe O, Ho PP, Chan SM, Chang A, Higgins JP, Tomooka BH, Thomas FM, Song JJ, Goodman SB, et al.: Selective tyrosine kinase inhibition by imatinib mesylate for the treatment of autoimmune arthritis. J Clin Invest 2006, 116: 2633-2642.

66. El Hajj Dib I, Gallet M, Mentaverri R, Sevenet N, Brazier M, Kamel $\mathrm{S}$ : Imatinib mesylate (Gleevec) enhances mature osteoclast apoptosis and suppresses osteoclast bone resorbing activity. Eur J Pharmaco/ 2006, 551:27-33.

67. Leslie D, Lipsky PE, Notkins AL: Autoantibodies as predictors of disease. J Clin Invest 2001, 108:1417-1422.

68. Samuels J, Ng YS, Coupillaud C, Paget D, Meffre E: Impaired early $B$ cell tolerance in patients with rheumatoid arthritis. $J$ Exp Med 2005, 201:1659-1667. 
69. Keystone E: B cell targeted therapies. Arthritis Res Ther 2005, 7(Suppl 3):S13-S18.

70. Looney RJ: B cell-targeted therapy for rheumatoid arthritis: an update on the evidence. Drugs 2006, 66:625-639.

71. Stohl W: Therapeutic targeting of $B$ lymphocyte stimulator (BLyS) in the rheumatic diseases. Endocr Metab Immune Disord Drug Targets 2006, 6:351-358.

72. Leipe J, Skapenko A, Lipsky PE, Schulze-Koops H: Regulatory $\mathbf{T}$ cells in rheumatoid arthritis. Arthritis Res Ther 2005, 7:93-99.

73. Skapenko A, Leipe J, Lipsky PE, Schulze-Koops H: The role of the $\mathrm{T}$ cell in autoimmune inflammation. Arthritis Res Ther 2005, 7(Suppl 2):S4-S14.

74. Lawson C, Brown A, Bejarano V, Douglas S, Burgoyne C, Greenstein A, Boylston A, Emery P, Ponchel F, Isaacs J: Early rheumatoid arthritis is associated with a deficit in the CD4 ${ }^{+} \mathrm{CD} 25^{\text {high }}$ regulatory $\mathrm{T}$ cell population in peripheral blood. Rheumatology 2006, 45:1210-1217.

75. Sakaguchi S, Ono M, Setoguchi R, Yagi H, Hori S, Fehervari Z, Shimizu J, Takahashi T, Nomura T: Foxp3 ${ }^{+} \mathrm{CD}_{25} \mathrm{CD}^{+}$natural regulatory $\mathrm{T}$ cells in dominant self-tolerance and autoimmune disease. Immunol Rev 2006, 212:8-27.

76. Wan YY, Flavell RA: The roles for cytokines in the generation and maintenance of regulatory T cells. Immunol Rev 2006, 212:114-130.

77. Zorn E, Nelson EA, Mohseni M, Porcheray F, Kim H, Litsa D, Bellucci $\mathrm{R}$, Raderschall E, Canning $\mathrm{C}$, Soiffer $\mathrm{RJ}$, et al.: IL-2 regulates FOXP3 expression in human $\mathrm{CD} 4{ }^{+} \mathrm{CD} 25^{+}$regulatory $\mathrm{T}$ cells through a STAT-dependent mechanism and induces the expansion of these cells in vivo. Blood 2006, 108:1571-1579.

78. Gonzalez-Rey E, Fernandez-Martin A, Chorny A, Delgado M: Vasoactive intestinal peptide induces $\mathrm{CD} 4^{+}, \mathrm{CD} 25^{+} \mathrm{T}$ regulatory cells with therapeutic effect in collagen-induced arthritis. Arthritis Rheum 2006, 54:864-876.

79. Hata H, Sakaguchi N, Yoshitomi H, Iwakura Y, Sekikawa K, Azuma Y, Kanai C, Moriizumi E, Nomura T, Nakamura T, et al. Distinct contribution of IL-6, TNF- $\alpha$, IL-1, and IL-10 to T cell-mediated spontaneous autoimmune arthritis in mice. J Clin Invest 2004, 114:582-588.

80. Hirota K, Hashimoto M, Yoshitomi H, Tanaka S, Nomura T, Yamaguchi T, Iwakura Y, Sakaguchi N, Sakaguchi S: T cell self-reactivity forms a cytokine milieu for spontaneous development of IL-17 ${ }^{+}$Th cells that cause autoimmune arthritis. J Exp Med 2007, 204:41-47. 